relative impermeability of the choroid to these substances. Bromide and chloride ions in the extracellular fluid are treated identically ; in the formation of cerebrospinal fluid, however, there appears to be some selection by the choroid in favour of chloride; consequently the bromide level in the C.S.F. is rather lower than the blood level.

\section{Vulval Varicosities}

Q. -What treatment is advised for vulval varicosities after the childbearing period? The patient in question is 65 and had bilateral white leg 30 years ago.

A.- The veins of the vulva drain into the long saphenous system. Vulval varicosities are usually therefore due to incompetence of this system, the treatment of which involves Trendelenburg's operation; they are, however, a rare component of this syndrome except in pregnancy, when they usually subside naturally in the puerperium. If large the vulval varicosities can be excised as well. Treatment by injection is contraindicated. Very occasionally vulval varicosities may be traced to an incompetent perforating vein in the thigh.

The fact that this patient has had bilateral white leg is of some importance, as the varicosities here may be secondary to the thrombosis of the deep veins; or, by now, to their recanalization and incompetence, from which she may have other symptoms. The function of the deep veins should be assessed, preferably by a phlebogram. If the femoral vein is patent although incompetent, treatment of the varicosities is as described above. If, however, the femoral vein is blocked so that the varicosities may be acting as collaterals, Trendelenburg's operation should not be done and the varicosities are best left alone. However, if they are huge and threatening to burst they may be removed, though they will probably recur later.

Finally, with vulval varicosities care should be taken to exclude the presence of a pelvic tumour.

\section{Lupus Erythematosus and Sunlight}

Q.-What place have anti-sunburn applications in the management of conditions such as chronic lupus erythematosus, where sunlight is thought to be an exacerbating factor? If useful, what preparations are advised?

A.- Many believe that those rays of the sun which cause sunburn may activate lupus erythematosus in exposed skin, and some claim that typical lesions have been produced by radiation from mercury vapour arc-lamps. It is well, therefore, to warn patients with such a disorder to avoid bright sunlight and always to wear a hat that shades the face, ears, and neck. Reflected light, as from water, is, of course, almost as dangerous as direct sunlight.

Anti-sunburn applications form only a small part of the treatment, for unless they are applied so thickly as to be disagreeable they are not entirely effective in preventing the sun's rays from reaching the skin. In women, ordinary face cream followed by liberal use of powder tinted with orange is helpful. Special ointments containing one or more of those substances known to absorb the erythema-producing rays of the sun, such as para-aminobenzoic acid, methyl salicylate, tannic acid and esculin (a glycoside from the bark of the horse-chestnut used as a protective against sunburn), $5-10 \%$ of each, are most effective, but occasionally lead to contact dermatitis or sensitization. Soft yellow paraffin is also effective, though not entirely satisfactory cosmetically.

\section{NOTES AND COMMENTS}

Release Pain as Sign of Peritonitis.-Dr. E. F. Blumberg (London, S.W.3) writes: I read with very great interest your answer about release pain ("Any Questions?" November 2, p. 1063). The answer, however, is not correct, as the sign is not produced as originally described. The release pain, or ebound sign, as described by my father, Dr. M. Blumberg, in 1907, depends on the comparison in strength between two different types of pain. ${ }^{12}$ Steady pressure is exerted over the suspected area, and while this is being done the patient is asked what kind of pain he feels. After he has given his answer, pressure is suddenly released by lifting the palpating hand abruptly. Now the patient is asked again which one of the two pains is stronger. Often the answer can be read in his face. In case the second pain is stronger, peritoneal involvement is certain.

To estimate prognosis and development of a suspected intraabdominal lesion, as parametritis, appendicitis, cholecystitis, o an abscess, examinations are carried out at intervals of a few hours. If, at first, pressure pain is less than rebound pain, and later on both pains are the same, the lesion is subsiding. In a developing attack, pressure and release pain may be the same to begin with, but the latter will be more pronounced the more time has elapsed. Used in this manner, Blumberg's sign is most reliable, as it excludes the difference between individual thresholds of pain, eliciting two different pains in the same person. Large distending tumours may prevent its use. When used in suspected cholecystitis, an acute inflammation of the pleura must be excluded, as the sign may be found positive in these cases.

OUR EXPERT replies: Dr. M. Blumberg first described "release pain " in 1907,1 and gave further details of its use as a means of indicating whether peritonitis is spreading or not in his paper on the prognosis and indications for operation in appendicitis and peritonitis in $1910 .^{2}$ What the sign demonstrates is that in peritonitis an abrupt movement of the parietal peritoneum is more painful to the patient than steady pressure. The diagnosis of acute appendicitis with early peritonitis can nearly always be made by gentle palpation without submitting the patient to the additional pain of an abrupt movement. As all cases of acute peritonitis in which there is any doubt whether spreading peritonitis is present or not should be submitted to urgent operative treatment, reliance on a single physical sign may be misleading and if used to indicate a prognosis may give rise to dangerous delay in instituting the proper treatment.

\section{REFERENCES}

1 Blumberg, M., Münch. med. Wschr., 1907, 54, 117. 2 Berl. klin. Wschr., 1910, 74, 139.

Effect of Adoption on Fertility.-Dr. J. D. BaEYerTz (London, E.9) writes: In answer to a recent query on this subject " Any Questions?" September 21, p. 719) my own findings may be of interest. Having always been impressed in antenatal clinics by the number of infertile women who conceived shortly after adopting a child, I investigated (not without some difficulty) the incidence of this phenomenon in Auckland, New Zealand. I was surprised to find that only $8 \%$ of women conceived after adoption, probably no more than could be expected by chance alone Coincidentally, this result was identical with that obtained by Hansen and Rock $^{1}$ from a similar survey in America.

\section{REFERENCE}

1 Hansen, F. M., and Rock, J., Amer. J. Obstet. Gynec., 1950, 59, 311

Correction.-In the paper on "Peripheral Artery Grafting, by $\mathrm{Mr}$. Peter Martin (August 17, p. 371), there were some mistakes in the figures quoted in the section headed "Results and Discussion" (p. 375). In the first paragraph: the later series of cases amounted to 51 (not 31). In the third paragraph : 58 (not 88 ) by-pass grafts were inserted, and 50 (not 30 ) of the patients were male. In the fifth paragraph: 47 (not 58) arterial homografts were used, and 37 (not 48) grafts were patent two to eight months after operation.

Collected Articles from the " British Medical Journal "

The following books are available through booksellers or from the Publishing Manager, B.M.A. House. Prices, which include postage, are now the same for both inland and overseas. Emergencies in General Practice (26s. 9d.).

Refresher Course for General Practitioners, Volumes 2 and 3 (26s. 9d. each)

Clinical Pathology in General Practice (22s. 3d.)

Any Questions?, Volumes 2 and 3 (8s. 3d. each).

All communications with regard to editorial business should be addressed to THE EDITOR. BRITISH MEDICAL JouRnal, B.M.A. House, TAVISTOC SOUARE, LONDON, W.C.1. TELEPHONE: EUSTON 4499. TELFORAMS Aitiology, Westcent, London. ORIGINAL ARTICLES AND LETTER forwarded for publication are understood to be offered to the British Medical Journal a'one unless the contrary be stated.

Authors desiring REPRINTS should communicate with the Publishing Manager. B.M.A. Hcuse, Tavistock Square, W.C.1, on receipt of proofs. ADVERTISEMENTS should be addressed to the Advertisement Director, B.M.A. House. Tavistock Square, London, W.C.1 (hours 9 a.m. to 5 p.m.) TELEPHONE: EUSTON 4499. TELEGRAMS: Britmedads, Westcent, London. MEMBERS' SUBSCRIPTIONS should be sent to the SECRETARY of the Association. TElePHONE: EUSTON 4499. Telegrams: Medisecra. Westcent, London.

B.M.A. Scotrish OFfice: 7, Drumsheugh Gardens, Edinburgh. 